\title{
DO NOT HATE THE PLAYERS THE DIGITAL ADVERTISING ECOSYSTEM AND ITS ACTORS
}

\author{
Valerio Stallone \\ Zurich University of Applied Sciences, Center for Digital Marketing \\ Stadthausstrasse 14, CH-8400 Winterthur, Switzerland
}

\begin{abstract}
This paper presents a systematic review of the literature of 29 research articles, which used a visualization of the digital advertising ecosystem with a focus on online real-time advertising. This review aims to address a gap in the literature by identifying a standardization of digital advertising ecosystem visualization and explanation. Achieving this aim will bring together fragmented literature to serve as a foundation for research into digital advertising ecosystems and other related research. There are discrepancies, which imply different understandings of how the advertising ecosystem elements work and communicate. This work should minimize the risk of wrong conclusions in literature as well as in practice. The author therefore recommends a visualization; future researchers should challenge.
\end{abstract}

\section{KEYWORDS}

Digital Marketing, Display Advertising, Programmatic Advertising, Real-Time Bidding, Digital Advertising Ecosystem

\section{INTRODUCTION}

Visiting a website or opening a free app often results in a certain amount of frustration. This paper focuses on the advertising technology applications and players that build an ecosystem, which enables publishers to connect to advertisers. In the ecosystem that has evolved in literature, the author finds a setting of intermediaries who are taking part in an auction, which connects buyers and sellers of a unique, indivisible good: The impression (Feldman et al., 2010). Stallone \& Klaas have tried to keep up with the pace by modelling and analyzing different aspects of marketing technology adaptations (Stallone and Klaas, 2019). In their paper they have analyzed literature, which discussed at least two elements of the digital advertising ecosystem ("DAE") and dated 2015 or younger. By doing so, they were able to recommend a visualization of the DAE, which future researchers could have been relying upon for their studies. In this review, the author will enlarge the set of articles as well as presenting a new methodological approach to the literature review. In the last chapter, the author suggests an updated version of the standardization of the DAE visualization for scientific literature as well as for work in non-academic fields.

\section{LITERATURE REVIEW}

Attention is the resource advertisers and publisher depend upon: Muthukrishnan first stated this known concept in a digital framework in the end of the last decade (Muthukrishnan, 2009). Muthukrishnan also mentioned, that "the way of selling and buying ads on the Internet via an exchange (market) brings sellers (supply) and buyers (demand) together" (Muthukrishnan, 2009). The seller supplies inventory as well as human eyes, which the demand buys. This marketplace, the DAE, outgrew the simple exchange platform and added new elements to it: While keeping the supply, the demand, the market and the user side, researchers completed the DAE by the data side (Callejo, 2015; Yuan, 2015; Papadopoulos et al., 2017; Wang, Zhang and Yuan, 2017). So-called data management platforms have emerged to help advertisers merge and manage data in large volumes in order to make better buying decisions (Nicholls, Malins and Horner, 2013). 


\section{RESEARCH METHOD}

This review investigates the digital advertising ecosystem from a multidisciplinary perspective. The author selected peer-reviewed articles from four bibliographic databases (IEEE Xplore, Sage journals online, Science Direct \& Google Scholar). The author considered peer-reviewed journals and conference proceedings based no their knowledge validity and their highest impact on the research field. To ensure the relevance of the articles in this study, the author used a combination of four keywords. Each of the selected articles is required to contain one of the following combinations of keywords at least in the abstract:

1. *digital advertising* AND *ecosystem*

2. *display advertising* AND *ecosystem*

3. *programmatic advertising* AND *ecosystem*

4. *real time bidding* AND *ecosystem*

After the first research round, the author found himself with a lack of content. This is why he enlarged the methodology by five combinations of keyword research and content analysis:

5. *ad exchange* AND containing a figure showing a visualization of an ecosystem

6. *data management platform* AND containing a figure showing a visualization of an ecosystem

7. *ad server* AND containing a figure showing a visualization of an ecosystem

8. $* \mathrm{dsp}^{*} / *$ demand side platform* AND containing a figure showing a visualization of an ecosystem

9. *ssp*/*supply side platform* AND containing a figure showing a visualization of an ecosystem

The search of articles was limited to English \& German speaking journals between 2013 \& 2019. The rationale is to capture the latest change in investigating the digital advertising ecosystem. The first search generated 112 articles, which were further limited to those visualizing the digital advertising ecosystem. Finally, the author included 29 articles.

\section{DESCRIPTIVE RESULTS}

The author analyzed the reviewed literature on year of publication, theoretical framework and content differences.

\subsection{Year of Publication}

Table 1 shows that the highest number of publications between in 2017, which slightly declined in 2018 . The trend is evident: Researchers obviously make use of a visualization of the DAE in their analyses, whereas the need is growing more and more. 
Table 1 . The overview of the reviewed papers

\section{Amount of publications}

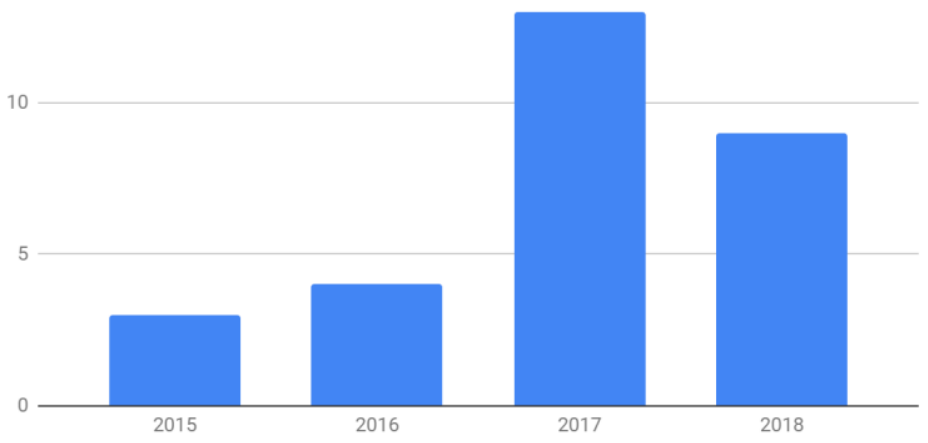

\begin{tabular}{|c|c|c|c|c|}
\hline Year & 2015 & 2016 & 2017 & 2018 \\
\hline Amount & 3 & 4 & 13 & 9 \\
\hline Authors & $\begin{array}{l}\text { (Callejo, 2015; } \\
\text { Trofimov, } \\
\text { Arsiriy and } \\
\text { Arsiriy, 2015; } \\
\text { Yuan, 2015) }\end{array}$ & $\begin{array}{l}\text { (Chen } \text { et al., 2016; } \\
\text { Dwyer and } \\
\text { Kanguri, 2016; } \\
\text { Yamaguchi et al., } \\
\text { 2016; Zhou and } \\
\text { Shariat, 2016) }\end{array}$ & $\begin{array}{l}\text { (Chaudhuri, } \\
\text { Bagherjeiran and } \\
\text { Liu, 2017; Chen et } \\
\text { al., 2017; Sayedi } \\
\text { et al., 2017; } \\
\text { Wang, Zhang and } \\
\text { Yuan, 2017; } \\
\text { Dwyer and } \\
\text { Kanguri, 2017; } \\
\text { Gardh and Amnäs, } \\
\text { 2017; Högström } \\
\text { and Wallin, 2017; } \\
\text { Kumar, 2017; Niu } \\
\text { et al., 2017; } \\
\text { Papadopoulos et } \\
\text { al., 2017; Qin, } \\
\text { Yuan and Wang, } \\
\text { 2017a, 2017b) }\end{array}$ & $\begin{array}{l}\text { (Aksu } \text { et al., 2018; } \\
\text { Alaimo and Kallinikos, } \\
\text { 2018; Arab et al., 2018; } \\
\text { Gupta and Mishra, } \\
\text { 2018; Haider } \text { et al., } \\
\text { 2018; Iordanou } \text { et al., } \\
\text { 2018; Parssinen } \text { et al., } \\
\text { 2018; Qin, Yuan and } \\
\text { Wang, 2018; Zhang, } \\
\text { 2018) }\end{array}$ \\
\hline
\end{tabular}

This academic development reflects itself in the industry: Programmatic advertising has turned into a globally 200-billiondollars per annum business (Parssinen et al., 2018) and has grown, since 2014, at a 40\% year-on-year pace (Fisher, 2019).

\subsection{Theoretical Framework}

The DAE contains five different fields: demand side, supply side, market, data and the user (Wang, Zhang and Yuan, 2017). The advertisers represent the demand side: They bring in the monetary resources. The publishers represent the supply side: As stated above, they are responsible for the inventory as well as for the pair of eyes of the user. In the market, demand and supply meet to exchange the slot for money based on a second price auction (Zhang, 2018). Both, supply and demand side as well as third party actors, who enrich the information flow to make the user more transparent, create the data layer. The analysis of the literature - journals, book chapters, conference proceedings - controls for the presence of the five segments presented as well as the density of elements within those segments.

\subsection{Content Differences}

Visualizations of the digital advertising ecosystem vary from very simple versions with only three players (Alaimo and Kallinikos, 2018) to thirteen elements (Iordanou et al., 2018). Research report the time component differently: From the advertising request due to the HTML request of a user on supply side to the delivery of the ad, their opinions differ. Starting at less than 100ms (Yuan, 2015; Chaudhuri, Bagherjeiran and Liu, 2017; Papadopoulos et al., 2017; Parssinen et al., 2018), to around 100ms (Callejo, 2015; Chen et al., 2017; Niu et al., 2017; Gupta and Mishra, 2018; Iordanou et al., 2018), the opinions end at longer than 100ms (Dwyer and Kanguri, 2016, 2017; Kumar, 2017). 
Visualizations in literature differ in elements mentioned. Some researchers even ignore entire categories the author described in this chapter. It leads to ignoring the data part (19 out of 29), to not mentioning the user (8 out of 29). Six out of twenty-nine publications do not contain neither the data, nor the user segment. Out of the nine articles published in 2018, four were complete containing all groups (2017: 3 out of 13; 2016: 0 out of 4; 2015: 1 out of 3). This positive trend reflects the knowledge enrichment in this field.

\section{RESULTS}

The author conducted a review of DAE visualizations in literature. This analysis focused on the mentioning of at least two key players within the ecosystem. The author therefore created an ecosystem visualization (see Figure 1) based on a "minimum viable version" of the literature review. It reflects the version of Stallone \& Klaas with an important change: The user layer connects with the supplier and not with the demand side (Stallone and Klaas, 2019).

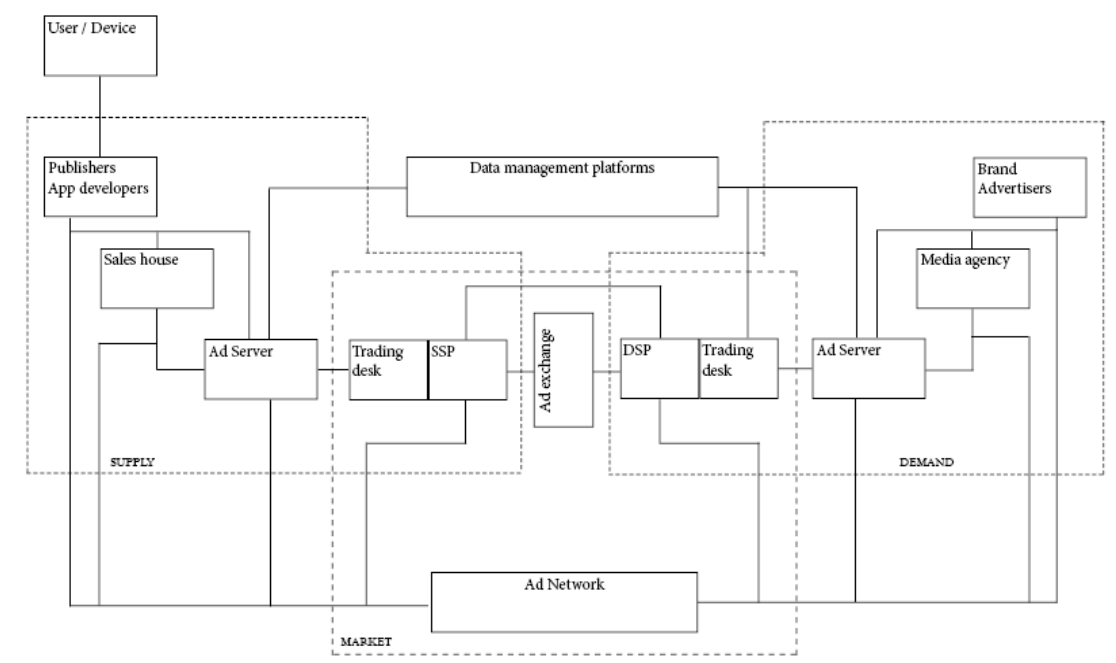

Figure 1. DAE according to the author

The five segments of the DAE are visible in Figure 1: User, Supply, Market, Demand and Data. On the supply side, the real-time bidding process starts when the user visits a publisher's website and then sends an advertising request to the Supply Side Platform. Publishers can also sell their advertising inventory through marketers. In addition to the supply side platform, there are other technical elements on the supply side such as the ad server or the trading desk. The demand side includes advertisers who often work with a media agency and who offer a demand side platform for advertising. As on the supply side, there are other technical elements on the demand side, such as ad servers and trading desks. The supply side and the demand side both use a data layer to target the advertising spaces. Therefore, there is a connection between the data layer and the ad servers of both sides. A central element in the ecosystem is the advertising exchange, which represents the market, where the trading of advertising inserts takes place.

\section{CONCLUSION}

The heterogeneity in the visualization itself is surprising: The fact that most of the papers did not represent the flow in its completeness reflects the lack of transparency of the ecosystem and its intermediaries. The rising trend in analyzing the field of programmatic advertising and of DAE shows the increasing interest of academia, which should reflect in a better understanding of the ecosystem and its functions. This paper presents a summarized version of the DAE, which scholars can use as a starting point for their analyses: By doing so and referring to it, they should be able to make sure to show all needed intermediaries involved in the DAE itself. 


\section{DISCUSSION}

There is still a lot of work to do in this field. In this chapter, the author presents possible limitations as well as potential further research for scholars to focus on in future.

\subsection{Limitations}

The focus of this review was on the digital advertising ecosystem visualization and not on the visualization of the digital advertising conceptual flow. Furthermore, this review looked at literature coming from different fields of academia (e.g. marketing, information technology, game theory).

\subsection{Further Research}

Future research should focus on the following questions: Does the industry and academia accept the DAE in Figure 1? If not, which elements are gone missing? The author therefore suggests carrying an in-depth description and qualitative analysis of the various descriptions displayed in scientific and nonscientific visualizations based on this paper and move the discussion to the public eye. As Parssinen mentioned, "there needs to be a significant awareness campaign to support transformation toward a healthier online advertising ecosystem" (Parssinen et al., 2018).

\section{REFERENCES}

Aksu, H. et al. (2018) 'Advertising in the IoT Era: Vision and Challenges', IEEE Communications Magazine, pp. 1-7. doi: 10.1109/MCOM.2017.1700871.

Alaimo, C. and Kallinikos, J. (2018) Objects, Metrics and Practices: An Inquiry into Programmatic Advertising, IFIP Advances in Information and Communi- cation Technology. San Francisco. Available at: https://www.researchgate.net/publication/327919972 (Accessed: 20 October 2018).

Arab, S. A. et al. (2018) 'Two-Layer Recommendation-Based Real Time Bidding (RTB)', in 2018 IEEE 27th International Conference on Enabling Technologies: Infrastructure for Collaborative Enterprises (WETICE). IEEE, pp. 91-94. doi: 10.1109/WETICE.2018.00024.

Callejo, P. (2015) Master on Telematics Engineering Auditing Methodology to Asses the Quality of Online Display Advertising Campaigns. Available at: http://eprints.networks.imdea.org/1483/1/TFM_Patricia_Callejo.pdf (Accessed: 20 October 2018).

Chaudhuri, S., Bagherjeiran, A. and Liu, J. (2017) 'Ranking and Calibrating Click-Attributed Purchases in Performance Display Advertising', in Proceedings of the ADKDD'17. doi: 10.1145/3124749.3124755.

Chen, G. et al. (2016) 'In-Depth Survey of Digital Advertising Technologies', IEEE Communications Surveys \& Tutorials, 18(3), pp. 2124-2148. doi: 10.1109/COMST.2016.2519912.

Chen, Y. et al. (2017) 'Measuring Network Reputation in the Ad-Bidding Process', in Detection of Intrusions and Malware, and Vulnerability Assessment. Springer, Cham, pp. 388-409. doi: 10.1007/978-3-319-60876-1_18.

Dwyer, C. and Kanguri, A. (2016) 'Gone in 200 Milliseconds: The Challenge of Blocking Malvertising', Student and Faculty Research Days, (3). Available at: http://digitalcommons.pace.edu/sfresearchdayhttp://digitalcommons.pace.edu/sfresearchday/3 (Accessed: 20 October 2018).

Dwyer, C. and Kanguri, A. (2017) 'Malvertising - A Rising Threat To The Online Ecosystem', Journal of Information Systems Applied Research. Association of Information Technology Professionals, Education Special Interest Group, 10(3), pp. 29-37. Available at: http://jisar.org/2017-10/n3/JISARv10n3p29.html (Accessed: 20 October 2018).

Feldman, J. et al. (2010) 'Auctions with Intermediaries', in EC '10 Proceedings of the 11th ACM conference on Electronic commerce, pp. 23-32. doi: https://doi.org/10.1145/1807342.1807346.

Fisher, L. (2019) US Programmatic Ad Spending Forecast 2019 - eMarketer Trends, Forecasts \&amp; Statistics, emarketer.com. Available at: https://www.emarketer.com/content/us-programmatic-ad-spending-forecast-2019 (Accessed: 29 May 2019).

Gardh, M. and Amnäs, U. (2017) Trading with digital ads. KTH. Available at: https://pdfs.semanticscholar.org/53de/e01d71afffc5b7f0290da2c6e0c5502d6dc5.pdf (Accessed: 20 October 2018). 
Gupta, S. and Mishra, A. (2018) 'Real Time Bidding With Comparative Study of Various User Responses Prediction Models', in International Conference on Recent Innovations in Management, Engineering, Science and Technology. Bareilly, p. 10. Available at: http://data.conferenceworld.in/IEEERAJSHREE/P493-502.pdf (Accessed: 29 October 2018).

Haider, C. M. R. et al. (2018) 'An ensemble learning based approach for impression fraud detection in mobile advertising', Journal of Network and Computer Applications, 112, pp. 126-141. doi: 10.1016/j.jnca.2018.02.021.

Högström, J. and Wallin, E. (2017) Programmatic Advertising: A Quantitative Study of Consumer Attitudes Towards Highly Frequent Online Ads. Halmstad University. Available at: http://www.divaportal.org/smash/get/diva2:1106048/FULLTEXT01.pdf (Accessed: 29 October 2018).

Iordanou, C. et al. (2018) 'Tracing Cross Border Web Tracking', in Internet Measurement Conference (IMC '18), October 31-November 2, 2018, Boston, MA, USA. Boston: ACM, p. 14. doi: 10.1145/3278532.3278561.

Kumar, J. (2017) 'Timeout Analysis, Troubleshooting and Notification in Real Time Bidding Advertising System with Implementation', Computer Science and Engineering, 7(3), pp. 67-78. doi: 10.5923/j.computer.20170703.01.

Muthukrishnan, S. (2009) 'Ad Exchanges: Research Issues', in. Springer, Berlin, Heidelberg, pp. 1-12. doi: 10.1007/978-3-642-10841-9_1.

Nicholls, S., Malins, A. and Horner, M. (2013) Real-Time Bidding in Online Advertising - The Death of the Mad Men. Available at: http://printarchiv.absatzwirtschaft.de/pdf/Studie_Real_Time_Bidding_in_Online_Advertising.pdf (Accessed: 20 October 2018).

Niu, C. et al. (2017) 'ERA: Towards privacy preservation and verifiability for online ad exchanges', Journal of Network and Computer Applications, 98, pp. 1-10. doi: 10.1016/j.jnca.2017.08.012.

Papadopoulos, P. et al. (2017) 'If you are not paying for it, you are the product: How much do advertisers pay to reach you?', in Proceedings of IMC '17, London, United Kingdom, November 1-3, 2017. London, p. 15. doi: $10.1145 / 3131365.3131397$.

Parssinen, M. et al. (2018) 'Is Blockchain Ready to Revolutionize Online Advertising?', IEEE Access, pp. 1-1. doi: 10.1109/ACCESS.2018.2872694.

Qin, R., Yuan, Y. and Wang, F.-Y. (2017a) 'Improving Auction Mechanisms for Online Real-Time Bidding Advertising with a Two-stage Resale Model', IFAC-PapersOnLine. Elsevier, 50(1), pp. 13575-13580. doi: 10.1016/J.IFACOL.2017.08.2372.

Qin, R., Yuan, Y. and Wang, F.-Y. (2017b) 'Optimizing the revenue for ad exchanges in header bidding advertising markets', in 2017 IEEE International Conference on Systems, Man, and Cybernetics (SMC). IEEE, pp. $432-437$. doi: 10.1109/SMC.2017.8122643.

Qin, R., Yuan, Y. and Wang, F.-Y. (2018) 'A Pareto optimal mechanism for demand-side platforms in real time bidding advertising markets', Information Sciences. Elsevier, 469, pp. 119-140. doi: 10.1016/J.INS.2018.08.012.

Sayedi, A. et al. (2017) Real-Time Bidding in Online Display Advertising. Available at: https://papers.ssrn.com/sol3/papers.cfm?abstract_id=2916875 (Accessed: 29 October 2018).

Stallone, V. and Klaas, M. (2019) The Digital Advertising Ecosystem Visualization - Literature Review. Available at: http://www.iadisportal.org/digital-library/the-digital-advertising-ecosystem-visualization-- -literature-review (Accessed: 29 May 2019).

Trofimov, B. F., Arsiriy, E. A. and Arsiriy, A. V. (2015) 'User identification problems on DSP side in terms of advertising RTB auctions', in 2015 Information Technologies in Innovation Business Conference (ITIB). IEEE, pp. 97-100. doi: 10.1109/ITIB.2015.7355063.

Wang, J., Zhang, W. and Yuan, S. (2017) Display Advertising with Real-Time Bidding (RTB) and Behavioural Targeting. Boston: now publishers inc. Available at: https://arxiv.org/pdf/1610.03013.pdf (Accessed: 29 October 2018).

Yamaguchi, Y. et al. (2016) 'Web Advertising Recommender System Based On Estimating Users' Latent Interests', in Proceedings of the 18th International Conference on Information Integration and Web-based Applications and Services. Singapore, pp. 42-49. doi: 10.1145/3011141.3011180.

Yuan, S. (2015) Supply Side Optimisation in Online Display Advertising. University College London. Available at: http://discovery.ucl.ac.uk/1463229/1/ShuaiYuan-PhD-thesis.pdf (Accessed: 20 October 2018).

Zhang, Y. (2018) Mathematical Approaches to Real Time Bidding Strategy (RTB) for Advertising Campaigns for Demand Side Platforms (DSP). NYU Available anghai. https://cdn.shanghai.nyu.edu/sites/default/files/zhang_yiyi_thesis_nyush_honors_2018.pdf (Accessed: 20 October 2018).

Zhou, B. and Shariat, S. (2016) 'Finding Needle in a Million Metrics: Anomaly Detection in a Large-scale Computational Advertising Platform', in Proceeding of the 2nd International Workshop on Ad Targeting at Scale. San Francisco. Available at: https://arxiv.org/pdf/1602.07057.pdf (Accessed: 20 October 2018). 